\title{
RESGATE DA MEMÓRIA MEDIADO PELA FOTOGRAFIA: ENSINO DE CIÊNCIA-TECNOLOGIA-SOCIEDADE PARA FORMAÇÃO INTEGRAL DO ALUNO DO ENSINO PROFISSIONAL
}

\author{
Rosângela Aquino da Rosa ${ }^{1}$, Sidnei Quezada Meireles Leite ${ }^{2}$ Maria Ciavatta ${ }^{3}$ \\ ${ }^{1}$ Programa de Pós-graduação Lato Sensu em Ensino em Ciências da Unidade Maracanã do Centro \\ Federal de Educação Tecnológica de Química de Nilópolis/RJ. E-mail: rosangelrosa@gmail.com. \\ ${ }^{2}$ Professor associado do Programa de Pós-graduação Stricto Sensu em Ensino em Biociências e Saúde da \\ FIOCRUZ; Professor Titular, Programa de Pós-graduação Stricto Sensu em Ensino de Ciências da \\ Unidade Nilópolis do Centro Federal de Educação Tecnológica de Química de Nilópolis/RJ. E-mail: \\ sidneiquezada@gmail.com. \\ ${ }^{3}$ Programa de Pós-graduação Stricto Sensu do Centro Federal de Educação Tecnológica de Química de \\ Nilópolis/RJ.
}

O objetivo deste trabalho foi analisar a história da mostra de projetos temáticos realizados por alunos do Ensino Profissional, durante a Semana Acadêmica da Unidade Maracanã do Centro Federal de Educação Tecnológica de Química de Nilópolis - RJ, a luz do movimento de Ciência - Tecnologia - Sociedade (CTS). Tratou-se de uma pesquisa teórico-empírica, descritiva, com abordagem qualitativa, apoiada em observações e dados construídos ao longo do trabalho com os sujeitos envolvidos. O objeto dessa pesquisa foram os 25 anos da mostra de projetos temáticos da Semana da Química, que surgiu em 1978 e ao longo dos anos, sofreu transformações na sua concepção e na forma de apresentação dos projetos. Entrevistas realizadas com ex-dirigentes, ex-professores, ex-alunos e com pessoas da administração de notório saber no campo da educação profissional demonstraram que o evento sofreu uma grande transformação ao longo dos últimos 10 anos, especialmente, após a instituição ter passado a ser CEFET, em 1999. As Feiras de Ciência e Tecnologia ultrapassaram os muros da escola demonstrando não apenas o talento e a capacidade dos alunos, mas também a sua importância para divulgação e popularização da ciência. O estudo mostrou que, nos últimos anos, o ensino de CTS está cada vez mais presente na mostra de projetos temáticos realizada durante a Semana da Química. Os projetos foram desenvolvidos numa perspectiva de abordagem temática, permitindo e requerendo uma abordagem interdisciplinar, o desenvolvimento deles contribuiu para formação de cidadania, isto é, para formação integral do aluno do Ensino Profissional.

Palavras-chave: memória, tecnologia, feira de ciência, educação científica, fotografia.

\section{INTRODUÇÃO}

As Feiras de Ciência e Tecnologia ultrapassam os muros da escola demonstrando não apenas o talento e a capacidade dos alunos, mas também a sua importância para divulgação e popularização da ciência. $O$ processo de desenvolvimento dos projetos passa pela aquisição e consolidação dos conhecimentos científicos e tecnológicos, atuando como agente complementador do ensino propedêutico (LEMOS e LEITE, 2005). Geralmente são apontadas como "celeiros de futuros cientistas", porque exercem um papel fundamental para a educação científica, servindo como motivadores para o desenvolvimento de projetos temáticos, pesquisa científica e tecnológica.

O movimento mundial de ensino de Ciência, Tecnologia e Sociedade (CTS) teve a sua origem no início da década de setenta e visava entender e discutir os impactos da ciência e da tecnologia na sociedade moderna (SANTOS e SCHNETZLER, 1997). Por outro lado, no Brasil na década de cinquienta houve o aparecimento de diversos 
projetos visando à melhoria do ensino de ciências (KRASILCHIK, 1987), o que veio a formar uma comunidade acadêmica, caracterizada pela autora, como educadores em ciência voltados para a construção da cidadania e que constituem, hoje, uma comunidade científica consolidada e focada em estudos para área de educação científica e tecnológica voltadas, especialmente, para o Ensino Médio.

Com relação à orientação do CTS para educação científica, verificamos que tem como objetivo promover a Alfabetização Científica e Tecnológica, um conceito que pode ser compreendido num sentido amplo como: a capacidade de ler, compreender e expressar opinião sobre assuntos de caráter científico (ACEVEDO, 2003). O que se pretende alcançar com isso é que todas as pessoas estejam preparadas para tomada de decisões responsáveis em questões controversas que envolvam relações CTS e que tenham impacto na qualidade de vida.

\begin{abstract}
[...] CTS, significa o ensino do conteúdo de ciência no contexto autêntico do seu meio tecnológico e social. Os estudantes tendem a integrar a sua compreensão pessoal do mundo natural (conteúdo da ciência) com o mundo construído pelo homem (tecnologia) e o seu mundo social do dia-a-dia (sociedade). Essas inter-relações de ciência - tecnologia - sociedade são sugeridas pelas setas da figura fazendo uso lógico do conteúdo da ciência. As setas pontilhadas representam as conexões feitas pelos materiais de ensino de CTS que fornecem o conteúdo de ciência neste contexto integrativo [...] (HOFSTEIN, 1988, p. 358).
\end{abstract}

A utilização das fotografias de época em pesquisas históricas, segundo afirma Luporini (2005), pode servir ao mesmo tempo como desencadeador da memória e desinibidor das falas, ajudando a elucidar determinados fatos e acontecimentos importantes da vida de uma determinada comunidade ou grupo, porém, é preciso o apoio de outras fontes. $\mathrm{Na}$ análise das fotografias temos outro problema metodológico: como fazer as fotos "falarem" àquele que as contempla? As imagens fotográficas, para fins de pesquisa histórica, impõem a necessidade de recorrer a outros tipos de textos referentes ao mesmo tema para sua interpretação (CIAVATTA, ROSA e LEITE, 2007).

O objetivo deste trabalho foi analisar a construção da Mostra de Projetos Temáticos da Semana de Química da Unidade Maracanã do CEFET de Química de Nilópolis/RJ, identificando através da memória coletiva registrada nas fotografias, os indícios do ensino de Ciência, Tecnologia e Sociedade, como promotoras de uma formação integral para alunos do ensino profissional. Para alcançar esse objetivo, foram utilizadas fotografias como fonte histórica, análise de documentos oficiais e entrevistas com alguns atores desse processo. 


\section{METODOLOGIA}

Trata-se de uma pesquisa teórico-empírica, descritiva, com abordagem qualitativa, apoiada em observações e dados coletados ao longo do trabalho com os sujeitos envolvidos. O estudo foi desenvolvido na Unidade Maracanã do Centro Federal de Educação Tecnológica de Química de Nilópolis - RJ, também denominada CEFET de Química de Nilópolis/RJ, situado na Rua Senador Furtado, 121, Maracanã, Rio de Janeiro, RJ, CEP 20270-021.

Esse trabalho teve como foco a semana anual de extensão, denominada Semana da Química, quando são realizadas atividades de divulgação e popularização da ciência, atividades culturais, atividades esportivas e a Mostra de Projetos Temáticos de alunos do Ensino Médio e Técnico. Esse evento acontece há 27 anos e sofreu modificações em função das conjunturas político-educacionais do país, inovações tecnológicas e cenário institucional.

Os sujeitos envolvidos na pesquisa foram os professores e alunos do Ensino Médio e Técnico do CEFET de Química de Nilópolis/RJ. A coleta de dados foi realizada a partir da análise de documentos oficiais da instituição, entrevistas abertas e questionários aplicados aos alunos e docentes do Ensino Médio e Técnico do CEFET de Química de Nilópolis/RJ, durante 2005.

O estudo estrutura-se a partir de entrevistas feitas com pessoas da administração de notório saber no campo da educação profissional, registros obtidos a partir das observações feitas pela autora, artigos, livros e periódicos da área de conhecimento. Foram analisadas as matrizes curriculares do Ensino Médio (EM) e Ensino Médio Integrado ao Técnico (EMIT), respectivamente, de 2003 e 2005. Além desses documentos oficiais, foram analisados Decretos, Portarias e Resoluções referentes à Educação Profissional e ao Ensino de Artes (PCNEM).

Participaram desta pesquisa 12 professores que atuam na Educação Profissional Técnica de diversas áreas de conhecimento, 2 ex-dirigentes e 2 exprofessores. Foram realizadas entrevistas com perguntas abertas que foram codificadas, tabuladas e analisadas, tendo como referencial a literatura de Lefèvre e Lefèvre (2000) e Bardin (1977). Antes de cada aplicação de entrevista, a pessoa era informada sobre a natureza da pesquisa e era pedida a concessão dos direitos sobre o depoimento.

Nas indicações metodológicas para o estudo selecionamos como vertentes de aproximação da fotografia como fonte histórica (FRANCO, 1994; ESSUS, 1990; OLIVEIRA, 1994). Também poderá ser empregada a sistemática utilizada por Chartier 
(1990), que usa fotografia como fonte histórica. A organização do acervo foi procedida com a classificação das fotos, a partir de cerca de 8 mil fotografias contidas no arquivo da instituição. A sistemática de organização do acervo de fotografia do CEFET de Química de Nilópolis/RJ foi construída com base na experiência relatada por Moraes e Alves (2004).

A etapa de catalogação das fotografias foi definida em conjunto por pesquisadores do Grupo de Pesquisa da professora Maria Ciavatta, da Faculdade de Educação da UFF. Então, foram definidas as seguintes etapas: (1) Contagem e separação cronológica das fotografias - primeiro critério utilizado para possibilitar o resgate histórico pretendido; (2) Separação (dentro da cronologia) por conteúdo/tema para definir as "entradas" (acesso para consulta) das fotografias; (3) Classificação por série e subsérie - nessa etapa trabalhou-se com mapa onde as séries iam sendo identificadas e gerando subséries; (4) Definição de um código de localização das fotografias pos pasta, álbum ou caixa; (5) Identificação numérica codificada para cada fotografia; (6) Criação de uma ficha de catalogação de imagens para referenciar e situar historicamente cada fotografia; (7) Catalogação das fotografias.

A catalogação seguiu a ordem cronológica de identificação e alguns temas foram sugeridos para definir a classificação. Essa etapa da pesquisa foi essencial para que se pudesse definir o recorte do estudo. Assim, ao observar o acervo verificou-se que a maior incidência de fotografias era de eventos ocorridos na Instituição nos últimos 25 anos e, mais especificamente, da Semana da Química.

\section{DESENVOLVIMENTO}

\subsection{Organização da Semana da Química}

Na Unidade Maracanã do CEFET de Química de Nilópolis/RJ, os projetos são apresentados numa Feira de Ciência e Tecnologia que ocorre dentro da Semana da Química (Quadro I), e que surgiu em 1978 com objetivo de divulgar a Instituição e promover o desenvolvimento e o aperfeiçoamento do aluno do Ensino Técnico. Desde sua criação, a presença de empresas sempre foi uma constante, seja com estandes apresentando seus produtos e serviços ou colaborando com patrocínios para os projetos. Nos últimos anos, os organizadores têm conseguido financiamento com a Fundação de Amparo à Pesquisa do Estado do Rio de Janeiro (FAPERJ), e isso tem promovido melhorias para a Semana da Química, implicando alterações no seu formato. Mas alguns elementos se mantêm desde a sua primeira versão, tais como: apresentação de 
projetos, estandes de empresas, o financiamento da instituição para o desenvolvimento dos projetos, a articulação com as escolas públicas para trazer alunos do ensino fundamental e médio e a presença de atividades artístico-culturais.

Os projetos possuem em seu escopo estratégias que podem gerar, no aluno, a
autonomia e, por consequiência, uma independência libertadora, a qual
permitirá o pensar e o agir sobre ações intencionais, independentes do
direcionamento linear e cartesiano empregado por algumas escolas na
condução da formação de seus alunos (Nogueira, 2005, p. 48).

O desenvolvimento dos Projetos Temáticos ocorre em etapas em que o aluno deixa de ser um receptor de informações, passando a atuar como produtor de conhecimento. Esse fato se concretiza quando o aluno realiza o projeto através da experimentação, pondo em prática o conhecimento teórico que antes adquiriu em sala de aula. Durante o desenvolvimento do projeto surgem as idéias e os alunos planejam as tarefas, que ao serem executadas promovem a integração dos conhecimentos. Nesse sentido, são percebidas algumas etapas que estão listadas a seguir: (1) levantamento bibliográfico; (2) escolha dos procedimentos de laboratório e separação dos reagentes, quando se trata de experimentos em laboratório; (3) coleta de material ou de exemplares, quando se trata de criação de uma exposição de ciência, ou de um levantamento histórico; (4) realização de visitas técnicas, quando se trata de trabalhos de campo; (5) entrevistas com profissionais relacionados aos processos em estudo; (6) definição das variáveis importantes para o processo e medições; (7) realização de experimentos no laboratório, quando se trata de trabalhos experimentais; (8) elaboração de um documento descritivo sobre o projeto; (9) planejamento de um roteiro básico para apresentação dos resultados aos visitantes; (10) apresentação dos resultados na Mostra de Projetos Temáticos.

Segundo Santos (1992), interdisciplinaridade é a colaboração entre várias disciplinas, através de programas de pesquisa, visando à integração e/ou à coordenação de conceitos, métodos e conclusões, com reciprocidade nas trocas, o que implica mútuo enriquecimento. Nesse sentido, a habilidade em utilizar teorias em comunhão com outros campos do saber pode ser um momento de crescimento, um lugar dinâmico e dialético, no qual, através da prática interdisciplinar, se constroem objetos de conhecimentos específicos e gerais. 
Quadro I. Relação dos temas da Semana da Química do CEFET de Química de Nilópolis/RJ ocorridas de 1998 até 2005.

\begin{tabular}{|c|c|l|}
\hline $\begin{array}{c}\text { Semana } \\
\text { da Química }\end{array}$ & $\begin{array}{c}\text { Ano da } \\
\text { realização }\end{array}$ & \multicolumn{1}{c|}{ Tema } \\
\hline XIX* & 1998 & Agroindústria. \\
\hline XX & 1999 & $\begin{array}{l}\text { Reciclagem, reaproveitamento, reutilização. Uso } \\
\text { racional dos recursos naturais. }\end{array}$ \\
\hline Não houve. & 2000 & \\
\hline XXI & 2001 & Sem tema. \\
\hline XXII & 2002 & Tecnologia e Qualidade de Vida. \\
\hline XXIII & 2003 & $\begin{array}{l}\text { DNA 50 anos - CEFET de Química de Nilópolis/RJ } \\
60 \text { anos. }\end{array}$ \\
\hline XXIV & 2004 & Água: uma questão de consciência. \\
\hline XXV & 2005 & $\begin{array}{l}\text { A ciência e a tecnologia na busca da qualidade de } \\
\text { vida. }\end{array}$ \\
\hline XXVI & 2006 & Ciência e Tecnologia para Sociedade. \\
\hline
\end{tabular}

(*) Início das Feiras Temáticas. Fonte: Jornal Mural do CEFET Química - Edições Diversas

Com relação à influência do contexto político-educacional do país, no Quadro II, estão apresentados recortes das falas obtidas durante as entrevistas realizadas com os professores com relação às modificações sofridas na Semana da Química ao longo dos anos, alguns professores demonstraram que percebiam uma abordagem muito acadêmica nos trabalhos apresentados nos primeiros eventos porque eram focados em assuntos estritamente universitários. Ao se deparar com a mudança dos modelos educacionais, também foi percebido pelos professores que a Semana da Química sofreu impactos no nível de participação e de abordagem. Esse também foi ressaltado pelas observações feitas nas fotografias - como, por exemplo, quando é feita a comparação da fotografia da Semana da Química de 1980 (Foto I), com a fotografia da Semana da Química de 2006 (Foto II).

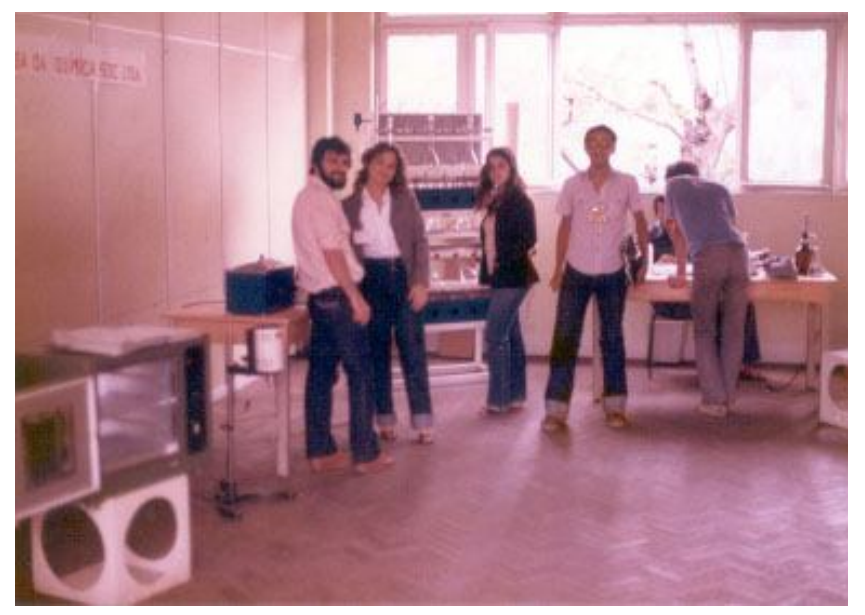

Foto I. Arquivo do Centro de Memória Fotográfica do CEFET de Química de Nilópolis/RJ. Entrada: Eventos. Tema/série: Semana da Química. Classificação: Mostra de Projetos $3^{\mathrm{a}}$ Semana da Química. Local: Dependências do CEFET/RJ. Ano: 1980. Autor desconhecido. No interior de 
uma sala de aula um experimento exposto na bancada ao fundo (à direita). Embora sendo durante a III Semana da Química, podemos notar que nesse período o evento não contava com um grande público circulante ainda. Não identificamos, além de uma frase ao lado esquerdo da parede, nenhum cartaz, recurso visual ou material explicativo.

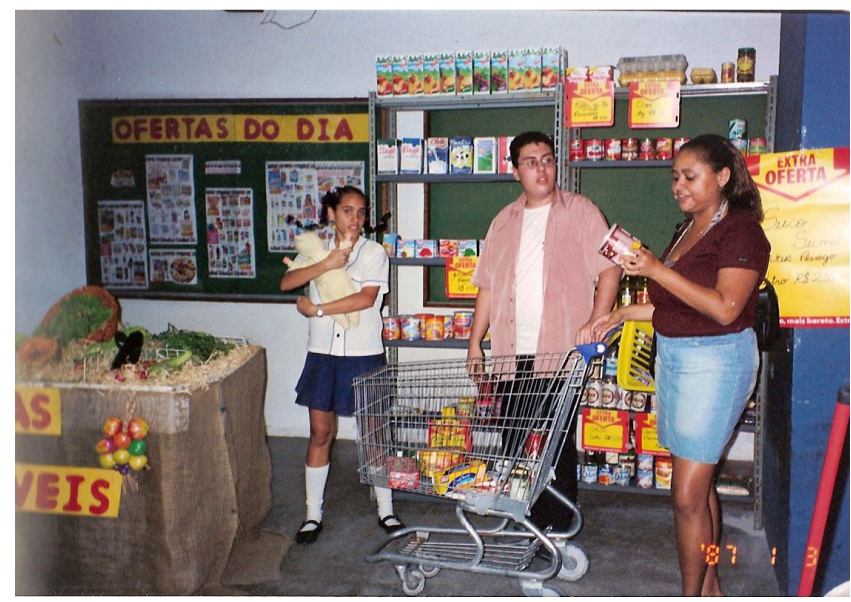

Foto II. Arquivo do Centro de Memória Fotográfica do CEFET de Química de Nilópolis/RJ. Entrada: Eventos. Tema/série: Semana da Química. Classificação: Mostra de Projetos. Local da foto: Unidade Maracanã. Ano: 2004. Autora: Rosângela Rosa. O Projeto apresentado intitulou-se: “Comprando Alimentos Seguros" e foi orientado pela professora Denise Perdomo. A imagem revela elementos de um contexto de supermercado dispostos em prateleiras e bancada, para dar maior veracidade cartazes com preços e promoções, comuns em supermercados completam o ambiente da encenação. A aluna que representa o papel da consumidora lê atentamente o rótulo antes de colocar o produto no carrinho de compras.

Quadro II. Entrevista com os professores sobre os impactos sofridos na Semana da Química ao longo dos anos.

\section{Como você as modificações sofridas na Semana da Química ao longo dos anos?} Você acha que houve influência do contexto político educacional do país?

Professor B. [...] Eu acho que, nas semanas da química de antigamente, alguns temas não eram abordados, até porque ainda estavam muito restritos a universidades.

Professor D [...] Sempre há essa relação direta entre as questões sociopolíticas e principalmente as questões ligadas a políticas educacionais, até porque nós somos uma instituição educacional. A mais gritante delas foi o modelo educacional adotado para a educação profissional no final dos anos 90, quando a gente passou a ter a separação estrutural do ensino médio dos cursos técnicos, quando os nossos alunos passaram a ter dupla jornada. E esse foi o período, no início de 98 até 2005. Que é quando a gente resgata o modelo de integrado, foi o período em que a semana da química sofreu maior interferência tanto do ponto de vista dos alunos não conseguirem se envolver porque estavam envolvidos obrigatoriamente em dupla jornada, que comprometeu, inclusive, a qualidade do ensino da instituição. (...) Nunca a semana da química foi abandonada, mas ela sofreu o impacto da não possibilidade de dedicação por parte dos alunos e também por parte dos professores, mas ela resistiu a isso, tanto que hoje ela continua. (...) Só que agora com essa nova política educacional, esse novo modelo que a escola adotou e esse diálogo entre os diferentes saberes da escola são novamente recuperados. 
As entrevistas revelaram que os professores percebem a Semana da Química como um elemento complementar para a formação profissional e de cidadania. No Quadro III estão apresentados os fragmentos das falas obtidas durante a entrevista feita com os professores da instituição relatando os impactos da Semana da Química na formação do aluno. Foi constatado que os professores percebem o processo de desenvolvimento dos projetos temáticos como sendo uma oportunidade para aprofundar os conhecimentos teóricos obtidos em sala de aula e tornando-os aplicados e voltados para situações cotidianas (sociedade).

O cotidiano oferece muitas manifestações que permitem o trabalho sobre pluralidade: os fatos da comunidade ou comunidades do entorno escolar, questões típicas de adolescentes e juventude, as notícias de jornal, rádio e $\mathrm{TV}$, programas e suplementos destinados a essa faixa etária específica, as festas locais. Além disso, o intercâmbio entre escolas de diferentes regiões do Brasil e de diferentes municípios de um mesmo estado, e a consulta a órgãos comunitários e de imprensa, inclusive na própria comunidade, são instrumentos pedagógicos privilegiados a serviço da formação de crianças e adolescentes. (BRASIL, 2004b, p. 138)

A pesquisa revelou que as metodologias empregadas eram, em sua maioria, experimentais (pesquisa empírica), seguida de pesquisa teórica e, finalmente, a pesquisa computacional e bibliográfica. $\mathrm{O}$ segundo aspecto de maior incidência refere-se ao compromisso da instituição com a sociedade. Percebeu-se que os professores viam nos alunos de projetos da Semana da Química uma contribuição na atuação profissional no mercado de trabalho e na melhoria de sua capacidade de interferência para mudar o futuro. Isso nos remete a uma das grandes questões do ensino de CTS que é a formação para cidadania. Na Foto II, um flagrante da presença do ensino de CTS na mostra de um projeto apresentado em 2004, usando um contexto de supermercado dispostos em prateleiras e bancada. A aluna que representava o papel da consumidora lia atentamente os rótulos antes de colocar o produto no carrinho de compras. O Projeto apresentado intitulava-se: "Comprando Alimentos Seguros"; e discutia a necessidade de conhecimento das informações apresentadas nos rótulos dos alimentos. 
Quadro III. Entrevista com os professores sobre os impactos da Semana da Química na formação do aluno.

Como você vê a semana da química contribuindo para formação dos alunos? Você acha que há uma contribuição para a formação de cidadania? Tem alguma contribuição pra formação do aluno?

Professor A. [...] Há uma formação de cidadania sim porque, eu disse, há uma interação, a gente abre as portas para visitação, há uma interação muito grande dos alunos com o público. E a contribuição científica é muito grande, porque o aluno extrapola o conhecimento teórico que ele tem, essa é a grande surpresa, essa é a grande maravilha da Semana de Química.

Professor C. [...] É fundamental pra aquele aluno que participa efetivamente dos projetos e vive a semana da química. Aproveita aquela semana. Por quê? Porque na medida em que você tem compromisso em apresentar um projeto, você tem que se comprometer com aquilo, então você tem que aprender a ter disciplina, pra você ler os artigos sobre aquele projeto, pra você vir aqui e apresentar o seu projeto, pra você elaborar o projeto. Então, de fato, isso influência na formação dele, né?

Professor D. [...] a gente vai pela preocupação de formar um cidadão em cima da sua formação integral. A semana da química desde o momento em que ele recebe o projeto, busca pelo professor orientador, vai buscar reforços pro seu projeto, vai buscar colegas pra equipe, ele passa a desenvolver conhecimentos, saberes, novas atitudes, respeito ao próximo, a divisão dos espaços a toda uma formação para conviver como cidadão dentro de uma sociedade.

Professor E. [...] Onde ele vai ver que ele tem limites e possibilidades. Que terá um papel social, papel científico de divulgação, mas também um papel social de compartilhar o conhecimento que ele adquiriu. Então toda essa mobilização, todo o evento mobiliza diferentes ações - desde a sua concepção até a sua apresentação. O tempo todo ele está crescendo como cidadão, ele está aprendendo, ele ta mobilizando conhecimentos que às vezes são descontextualizados, são usados em sala de aula, por mais que os professores tentem contextualizar, quando ele passa pela experiência de uma Semana da Química, num evento como esse, ele coloca em ação, ele mobiliza diferentes procedimentos, atitudes e valores que são fundamentais para essa formação dele.

O processo de desenvolvimento dos projetos possui um caráter interdisciplinar, com a interlocução entre as áreas de conhecimento propiciando valiosos momentos de aprendizagem para formação cidadã. Esses resultados mostraram que realmente pode ser constatada a presença dos princípios do movimento CTS perpassando a construção e apresentação da Semana da Química, em especial na mostra de projetos temáticos. Esse momento da Semana constituiu-se em um exemplo para comprovar as intervenções propositivas que são desencadeadas por alunos e professores com intuito de contribuir com a melhoria da qualidade de vida da sociedade.

\section{CONCLUSÕES}

A partir das discussões travadas ao longo deste trabalho, foi possível concluir que o processo de construção e realização da Semana da Química da Unidade Maracanã do Centro Federal de Educação Tecnológica de Química/RJ se constitui um processo de ensino de CTS, porque os alunos conseguiram adquirir conhecimentos 
científicos, tecnológicos e culturais e articulam esses conhecimentos com as situações do cotidiano e, às vezes, fazem propostas de soluções para os mesmos.

Com relação ao perfil institucional, quando se comparou o perfil da instituição em 1978, no início a Semana da Química com o perfil observado em 2004, pode-se concluir que as políticas educacionais impactaram de forma sensível a mostra de projetos temáticos. Por exemplo, em 2005, o CEFET de Química de Nilópolis/RJ passou a oferecer o Ensino Médio integrado ao Técnico, respaldado pelo Decreto $\mathrm{n}^{\circ}$. 5.154 de 2004 (BRASIL, 2004), possibilitando os alunos a terem uma atividade no contra turno, o que antes não era possível devido ao regime escolar de concomitância.

Do ponto de vista histórico, foi possível evidenciar nas fotografias, nos documentos oficiais e nos relatos dos professores que a Semana da Química se apropria cada vez mais das informações científicas e dos recursos tecnológicos, podendo ser atribuído, dentre outras causas, ao processo da globalização, à expansão da tecnologia de informação, à acessibilidade dos alunos às novas tecnologias e ao aumento da qualificação docente.

Partindo das concepções discutidas por Durant (2005), Auler e Delizoicov (2001) e Auler (2003), pode-se inferir que a construção da Semana da Química como estratégia de ensino complementar supera o ensino tradicional, contribuindo para a $\mathrm{ACT}$, porque os alunos tiveram a oportunidade de aperfeiçoar e desenvolver conceitos de Ciência e de Tecnologia, além de utilizar métodos científicos para realizar o projeto temático. Os projetos foram desenvolvidos numa perspectiva de abordagem temática, permitindo e requerendo uma abordagem interdisciplinar, o desenvolvimento deles contribuiu para formação de cidadania, isto é, para formação integral do aluno do Ensino Profissional.

\section{REFERÊNCIAS} ACEVEDO, J. A.; Cambiando la práctica docente em la enseñanza de las ciências através de CTS. Disponível em: <http:www.campinas-oei.org/salactsi>, 2003. Acesso em 25 de março de 2007.

ALVES, N.; Imagens das escolas, 2001. In: Alves, N.; Sgarbi, P. (org.). Espaços e imagens na escola. Rio de Janeiro: Editora DP\&A, 2001.

AULER, D; Delizoicov D.; Alfabetização científico-tecnológica para quê? Ensaio pesquisa em educação em ciências. vol. 03, nº 1, jun., 2001.

AULER, D.; Alfabetização científico-tecnológica: um novo paradigma? Ensaio pesquisa em educação em ciências. vol. 05, nº 1, mar., 2003. 
BARDIN, L.; Análise de conteúdo. Lisboa (Portugal): Edições 70. 1977.

BRASIL, Ministério da Educação. Secretaria de Educação Média e Tecnológica. Parâmetros Curriculares Nacionais: Ensino Médio, Diário Oficial da União, Brasília, 1999.

BRASIL, Ministério da Educação. Secretaria de Educação Média e Tecnológica. Orientações Curriculares do Ensino Médio: Ensino Médio. Diário Oficial da União, Brasília, 2004b.

CHARTIER, R.; A história cultural. Entre práticas e representações. Lisboa (Portugal): Editora DIFEL,1990.

CIAVATTA, M; Campello, A. M.; Do discurso à imagem - fragmentos da história fotográfica da reforma do ensino médio técnico no CEFET Química, 2006. In: Frigotto, G, Ciavatta M. A formação do cidadão produtivo. Editora INEP/MEC, Brasília, DF, 2006.

CIAVATTA, M.; Rosa, R. A. de; Leite, S. Q. M.; Ciência e Arte: O regaste da memória através da fotografia da educação profissional e tecnológica, 2007. In: Ciavatta, M. (org.), Memória e Temporalidades do Trabalho e da Educação. $1^{\circ}$. Edição, Editora Lamparina: Rio de Janeiro, 2007.

DURANT, J.; O que é alfabetização científica, 2005. In: Massarani L, Turney J, Moreira, IC (org.). Terra Incógnita - a interface entre ciência e público. Rio de Janeiro:Série Terra Incógnita, cap. 1, p. 13-39, 2005.

ESSUS, A. M. M.; Sob o signo da imagem: a produção da fotografia e o controle dos códigos de representação da classe dominante, no Rio de Janeiro, na primeira metade do século XX, Niterói, UFF, 1990.

FRANCO M. C.; A fotografia como fonte histórica. Introdução a uma coleção de fotos sobre a "escola do trabalho". Educação e Revista, Revista da Faculdade de Educação, UFMG, Belo Horizonte, 18/19. dez/jun., 1994.

HOFSTEIN, A.; Practical work and science education II. En P. Fensham (Ed.), Development and dilemmas in science education 1988. 189-217. Londres: Falmer Press. 2006. In: Dourado L. Concepções e práticas dos professores de Ciências Naturais relativas à implementação integrada do trabalho laboratorial e do trabalho de campo.

Revista Eletrónica de Enseñanza de las Ciências. vol. 05, nº 1, 2006.

KRASILCHIK M.; O professor e o currículo das ciências. São Paulo: EDU/EDUSP. 1987.

LEFÈVRE, F; LEFÈVRE A. M. C.; O discurso do sujeito coletivo - Um novo enfoque em pesquisa qualitativa (Desdobramentos). Caxias do Sul, RS: Editora EDUCS, 2000.

LEMOS, J. L. S.; LEITE S. Q. M.; Educação pela pesquisa por meio de um projeto temático de biologia no ensino médio: desenvolvimento de competências gerais. Anais do V Encontro Nacional de Pesquisa em Ensino de Ciências. Novembro, 2005. 
LUPORINI, T. J.; Memória e fontes iconográfica os desafios para a pesquisa em história da educação. Revista Diálogo Educacional, Curitiba, v. 5, n.14, p.147-175, jan./abr. 2005.

MORAES C. S. V.; Alves J. F. (org.); Resenha do Livro: Contribuição à pesquisa de ensino técnico no estado de são paulo: inventário de fontes documentais (197p.). Caderno de Pesquisa, Jan./Apr. 2004, vol.34, no.121, p.243-245. ISSN 0100-1574.

MAUAD A. M.; Através da imagem: fotografia e história interfaces. Revista Tempo. Departamento de História da UFF. I (2): 73-98. dez., 1996.

NOGUEIRA N. R.; Pedagogia dos projetos: etapas, papéis e atores. 1. ed. São Paulo: Editora Érica, 2005.

OLIVEIRA JÚNIOR, A.; Do reflexo à mediação. Um estudo de expressão fotográfica e da obra de Augusto Malta. Dissertação de Mestrado. Ed. Campinas. UNICAMP, 1994.

SANTOS W. L. P.; Schnetzler, R. P. Educação em Química: compromisso com a cidadania. Ijuí - RS: Ed. Unijuí, 144 p. 1997.

SANTOS W. L. P.; O ensino de química para formar o cidadão: principais características e condições e implantação na escola secundária brasileira.

Dissertação (Mestrado em Educação) Faculdade de Educação Universidade Estadual de Campinas, Campinas 1992. 